\title{
SCHWANNOMAS ARISING FROM UPPER EXTREMITIES- CLINICAL ANALYSIS OF RESULTS OF SURGICAL TREATMENT
}

\author{
Shivamurthy Kurudi1, Akshay Kulkarni², Ashwin S. Banakar ${ }^{3}$ \\ 1 Professor and HOD, Department of Plastic Surgery, SS Institute of Medical Sciences and Research Centre, Davangere, Karnataka. \\ ${ }^{2}$ Senior Resident, Department of Plastic Surgery, SS Institute of Medical Sciences and Research Centre, Davangere, Karnataka. \\ ${ }^{3}$ Resident, Department of Plastic Surgery, SS Institute of Medical Sciences and Research Centre, Davangere, Karnataka.
}

\section{ABSTRACT}

\section{BACKGROUND}

Schwannomas arise from the Schwann cells and are common benign neoplasms of the peripheral nerves. In our series, we present our experience of surgical treatment and analysis of results of excision of schwannomas.

\section{MATERIALS AND METHODS}

Clinical material consisted of 6 patients, amongst them 7 schwannomas located in the upper extremities were excised between 2014 and 2016. Five tumours had origin from major peripheral nerves and two from the small nerve branches. All the patients were treated surgically, and their results were analysed postoperatively. Symptomatic relief, early neurological deficiencies and the permanent motor deficiency was evaluated.

\section{RESULTS}

In the postoperative period, pain resolved in all the patients, paraesthesia in 4 and motor function in 5 , partial in 1 . Sensory function improved in 4 and partial in 2, which later improved completely. Median [2] and Ulnar [3] nerves were the commonly affected peripheral nerves. Small nerve branch Schwannomas were identified with the site of origin and carefully removed. Definitive healing was achieved in all the cases.

\section{CONCLUSION}

Schwannomas predominantly arise from ulnar and median nerves in the upper extremity. Slow growth of the tumour causes compression neuropathy of varying degrees, which is an indication for surgery. Improvement in the function of the peripheral nerve was achieved after excision of the schwannomas. The risk of development of permanent postoperative neurological deficit is very low.

\section{KEYWORDS}

Schwannomas, Upper Extremity, Surgical Treatment, Surgical Results.

HOW TO CITE THIS ARTICLE: Kurudi S, Kulkarni A, Banakar AS. Schwannomas arising from upper extremities- clinical analysis of results of surgical treatment. J. Evolution Med. Dent. Sci. 2018;7(16):2003-2006, DOI: 10.14260/jemds/2018/450

\section{BACKGROUND}

Schwannomas were described by Verocay in 1908 as benign neoplasms of the peripheral nerves.(1,2) Schwannomas occur in the third and fifth decades of life without racial or gender preponderance.(3.4) They develop as solitary tumours varying from $1-3 \mathrm{cms}$ in diameter,(5-7) although rare multiple tumours have been described.(8-14) Upper extremity schwannomas account for $12 \%$ to $19 \%$ and are located mostly on the volar surface.(15) Schwannomas constitute $8 \%$ of all the soft tissue tumours and are composed entirely of Schwann cells.(15,16) They are slow growing well encapsulated tumours and have a non-infiltrating growth pattern.(17,18) Expanding tumour mass displaces nerve fascicles. Clinical symptoms are attributed to the compression of nerve fascicles.(1,18) Magnetic resonance imaging is the preferred diagnostic tool, and on image scan tumour presents as well-defined fusiform mass within the nerve.

'Financial or Other Competing Interest': None.

Submission 05-03-2018, Peer Review 30-03-2018,

Acceptance 04-04-2018, Published 16-04-2018.

Corresponding Author:

Dr. Shivamurthy Kurudi,

\#271/2, $4^{\text {th }}$ Main Road,

PJ Extension, Davangere-577002,

Karnataka.

E-mail:drskurudi@gmail.com

DOI: $10.14260 /$ jemds $/ 2018 / 450$

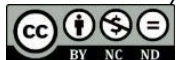

They look isointense to surrounding muscles on T1weighted images and hyperintense on $\mathrm{T} 2$ weighted images on intravenous administration of contrast medium neurogenic tumours show signal enhancement.(19-21) Many authors agree that on the basis of MRI findings, it is difficult to differentiate between malignant and benign tumours as well as between different types of benign tumours.(19-23) Histopathologically, schwannomas contain two different areas of varying proportion. ${ }^{17,24)}$ Highly cellular composed of spindle cells, which form palisade and produce Verocay bodies are called Antoni type A area. Mucinous matrix with loosely arranged Schwann cells are described as Antoni type B area.(24) In most of the tumours, one area will be predominant over the other area.(5) Rare variants of schwannomas are cellular, epithelioid melatonin and plexiform type. Monoclonal antibodies are used against proteins; S100, CD31, CD34 and GFAP in the immunohistochemical analysis in differential diagnosis of the peripheral nerve tumours.(17) Aim of this work is to present our experience in the management of upper extremity schwannomas and analyse the surgical results and the risk of development of new postoperative neurological deficits.

\section{MATERIALS AND METHODS}

Clinical material consisted of 3 males and 3 females. Age of the patients was from 16 to $72 \mathrm{yrs}$. with average of age $42.5 \mathrm{yrs}$. All patients were operated on for Schwannomas located in the upper extremity between 2014 and 2016. The patients were 


\section{Jemds.com}

scheduled for operation on the basis of clinical examination and diagnostic imaging findings and presence of symptoms such as pain, positive Hoffmann-Tinel sign, sensory impairment and motor deficits. Preoperative evaluation was done for anamnesis, physical examination of tumour, sensory function testing (pain, touch static and dynamic sensory discrimination), muscle tone and strength examination as well as testing for Hoffman-Tinel sign. To evaluate the sensory function and muscle strength of the upper extremity, modified BMRC scale was used. Surgical treatment results were evaluated using the scales mentioned above. Postoperative follow-up period was 1.5 to 2 yrs.

\section{RESULTS}

Location of the tumours. Schwannomas were located in the right upper extremity in 6 patients and one in left upper extremity. In total of 6 patients, 7 tumours were excised. Most of the Schwannomas originated from the major peripheral nerves, 3 from ulnar nerve, 2 from median nerve and 2 from the digital nerves. Two tumours from ulnar nerve at level of wrist, one proximal to wrist were removed. Two tumours from median nerve distal to elbow were removed. Two tumours from the digital nerves of the ring and middle fingers excised.

Preoperative examination in the group of tumours arising from major peripheral nerves revealed positive Hoffman-Tinel sign and paraesthesia in 4 out of 5 patients. Pain was present in 4 out of 6 patients. Pain was triggered by applying pressure to tumour in 3 patients, one patient suffered from night pain. Superficial sensory function disturbance was detected in 2 out of 6 patients and motor deficit in 1 out of 6 patients.

Histopathological reports in all of the excised and examined tumours showed pattern of typical schwannomas. Tumours from the small nerve branches had histopathological pattern of classical schwannomas (plexiform schwannomas).

Postoperative evaluation results. Recurrence was not observed in any of the patient in the follow-up period. Pain resolved in 5 patients. No relationship was observed between the presence of pain and the size of the tumour. Paraesthesia resolved in 4 patients who had suffered from it preoperatively. Hoffman-Tinel sign was negative in the postoperative course. New neurological deficit was observed in one patient. The tumour arising from the small nerve branches was excised in one piece with identification of the site of origin. After removal of tumours, definitive healing was achieved.

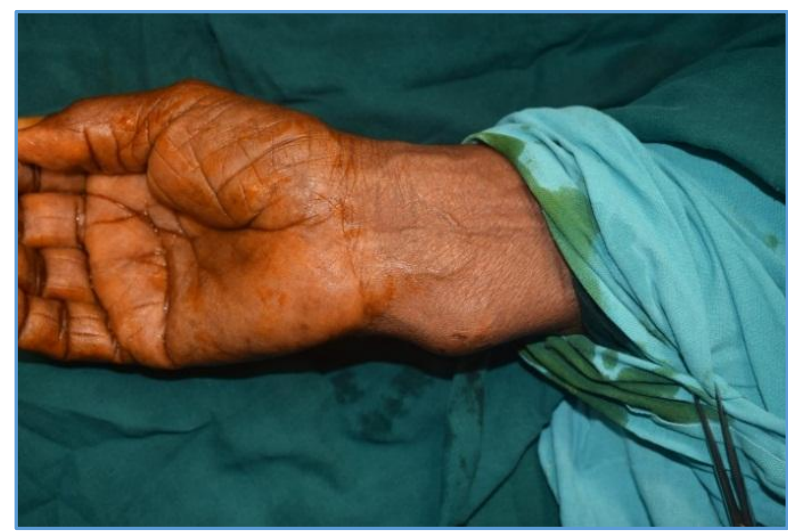

Figure 1. Schwannoma arising from Ulnar Nerve Rt. at Wrist
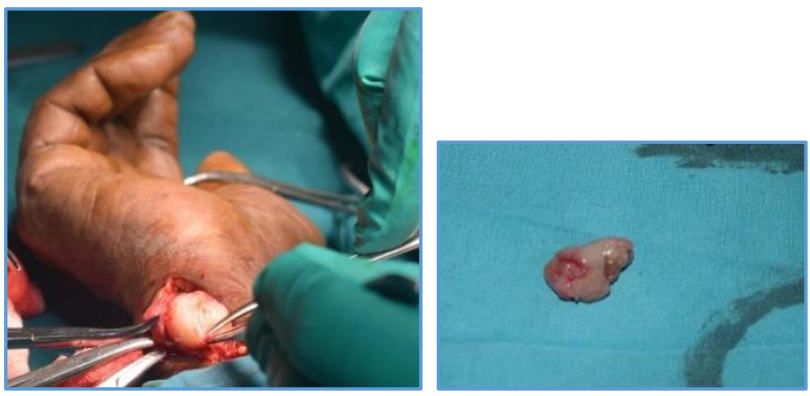

Figure 2. Intraoperative from Ulnar Nerve at Wrist

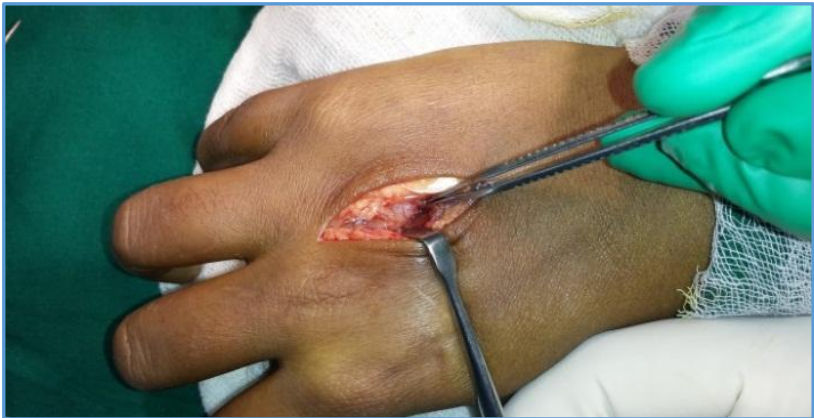

Figure 3. Rt. Hand arising from Digital Nerve

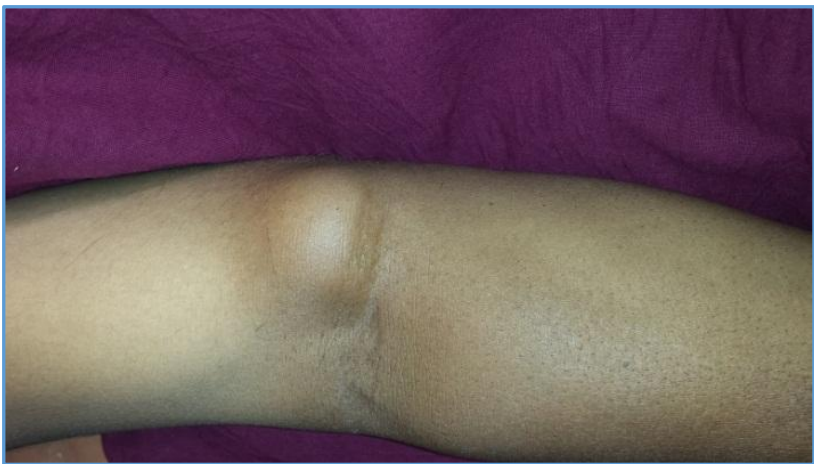

Figure 4. Schwannoma from Rt. Median Distal to Elbow
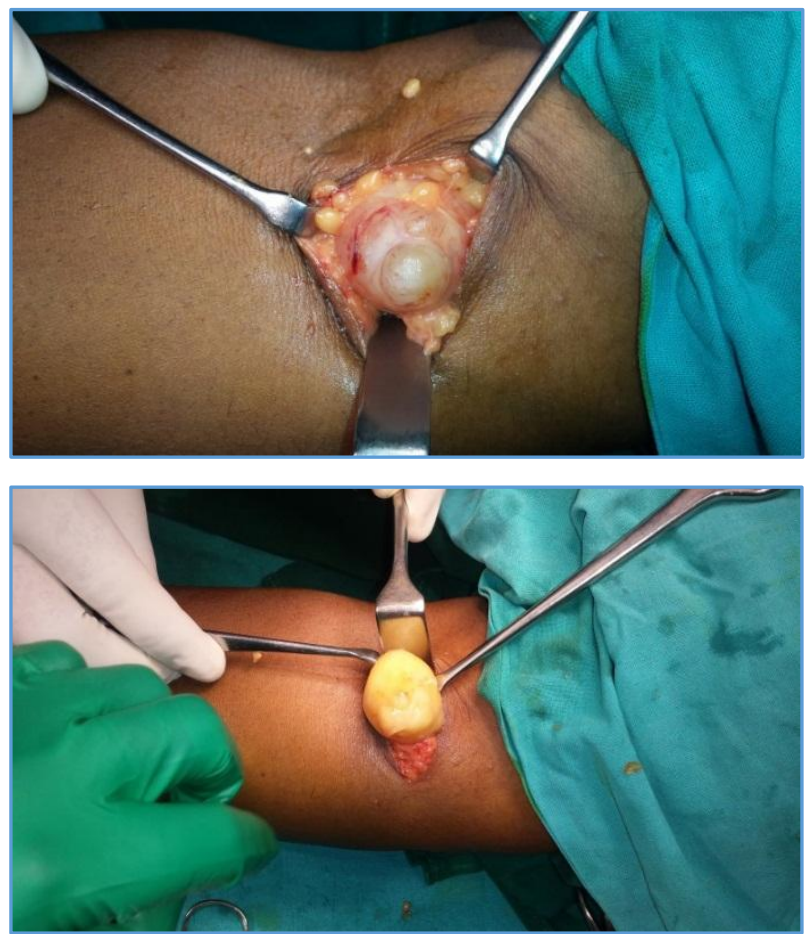

Figure 5. Intraoperative from Median Nerve 


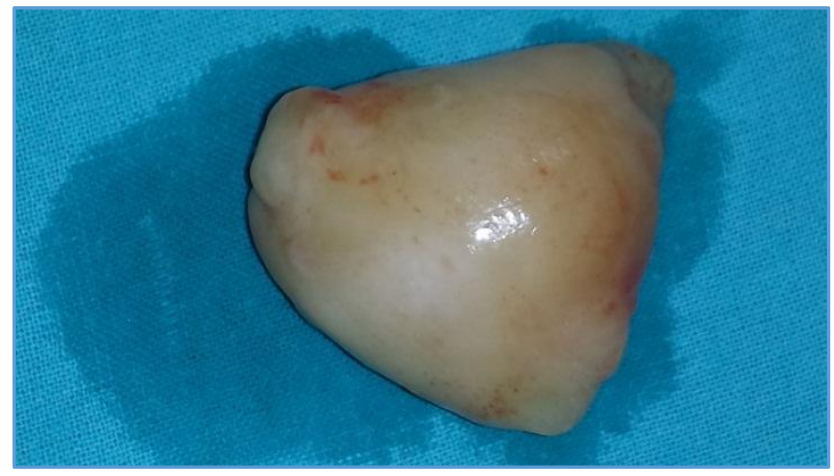

Figure 6. Excised Schwannoma from Median Nerve

\section{DISCUSSION}

In our study, schwannomas originated from the major peripheral nerves of the upper extremity. The common site of origin was ulnar, median and small nerves. After analysis of data from three major clinical centres comprising of 72 cases Siqueira et al described 12 cases had origin from ulnar nerve, 12 cases from median nerve and 3 cases from radial nerve. Date et al observed tumours of the upper extremity in descending order of frequency in ulnar, median and radial nerves in the clinical material consisted of 36 cases of schwannomas. The site of rare location of schwannomas is musculocutaneous nerve described by these authors. Adani et al established the most common site of origin of tumour in descending order of frequency are ulnar $n$ (14), median $n(3)$, musculocutaneous nerves 3 and digital nerves 3 tumours. In our study, none of the tumours were located in the axillary or musculocutaneous nerve. Tumours arising from the small nerve branches were located and the schwannomas arising from the major peripheral nerves were evenly distributed along the length of the upper extremity. Schwannomas mostly develop as solitary tumours.(5-7) Their growth is eccentric and non-infiltrating, can often be excised with or with only minimal damage to the fascicular structure. $(5,16,18)$ Adani et al in 2008 published an article comprising of 24 cases of upper extremity schwannomas. They were able to excise 20 tumours without damage to the fascicular structure. The risk of developing new postoperative neurological deficit is always a possibility in traumatic tumour excision. Their causative factors are diverse. Firstly, possibility of damage to the fascicles encircling the tumour during incision of the epineurium to be considered. Compression or irritation of the fascicles during dissection can cause nerve function impairment. Park et al concluded that transection of the fascicles during dissection of the tumour may result in new postoperative neurological deficits. Donner et al on the contrary has opined that fascicles entering the tumour are non-functional and their transection does not cause additional neurological deficit. The incidence of neurological deficiency after removal of schwannomas varies between 1.5 to 80 percent. $(5,10.12)$ Significantly, high percentage of complications occurs in the short-term period observations. Adani et al described worsening of paraesthesia in 23 out of 24 patients.(5) In the early postoperative period, which spontaneously resolved in all the patients within 12 months from the operation. Siqueira et al reported postoperative complication rate of $15.2 \%$ ( 11 out of 72 operated on patients). Majority of the reported deficits were transient. Eventually sensory impairment in 3 patients and motor deficit in 1 patient was observed out of 72 patients. Kim et al presented series of 30 schwannomas of the lower extremity with a complication rate in the early postoperative period of $76 \%$ and the neurological deficit in 2 of the operated patients. Kang et al published in 2000 with permanent sensory impairment in 1 out of 20 patients in his series.(10) Similarly, Knight et al observed serious postoperative complications in 5 out of 198 treated patients. In our study neurological deficit was observed in one patient postoperatively, which improved completely in the follow-up period of 6 months. During final clinical evaluation of our patients, we observed no new neurological deficit. At most, there was no improvement in certain neurological functions that had been impaired during preoperative evaluation. It has been confirmed in several studies that schwannomas can rarely impair motor function.(7) Neural tumours producing motor deficit should always arise a high suspicion of malignancy. In our opinion, patients with benign tumours may also show motor impairment preoperatively.

\section{CONCLUSION}

1. Schwannomas in upper extremities predominantly arise from major peripheral nerves. Most common nerves of origin are ulnar nerve and the median nerve.

2. The risk of exacerbation of compression neuropathy caused by gradual tumour growth justifies surgical excision in symptomatic nerve tumours.

3. With the use of adequate operative techniques in most cases, improvement in peripheral nerve function after the excision of schwannomas is achieved.

4. The risk of development of new permanent postoperative neurological deficit is low.

\section{REFERENCES}

[1] Rosenberg AE, Dick HM, Botte MJ. Benign and malignant tumors of peripheral nerve," in Operative Nerve Repair and Reconstruction, vol. 2, pp. 15871619, JB Lippincot Company, Philadelphia, Pa, USA, 1991.

[2] Gosk J, Zimmer K, Rutowski R. Peripheral nerve tumours-diagnostic and therapeutical basics. Folia Neuropathologica 2004;42(1):31-5.

[3] Zhou J, Man XY, Zheng M, et al. Multiple plexiform schwannoma of a finger. Eur J Dermatol 2012;22(1):149-50.

[4] Pilavaki M, Chourmouzi D, Kiziridou A, et al. Imaging of peripheral nerve sheath tumors with pathologic correlation: pictorial review. Eur J Radiol 2004;52(3):229-39.

[5] Adani R, Baccarani A, Guidi E, et al. Schwannomas of the upper extremity: diagnosis and treatment. Chir Organi Mov 2008;92(2):85-8.

[6] Kehoe NJ, Reid RP, Semple JC. Solitary benign peripheral nerve tumours. J Bone Joint Surg $\mathrm{Br}$ 1995;77(3):497-500.

[7] Malizos K, Ioannou M, Kontogeorgakos V. Ancient schwannoma involving the median nerve: a case report and review of the literature. Strategies in Trauma Limb Reconstr 2013;8(1):63-6.

[8] Barre PS, Shaffer JW, Carter JR, et al. Multiplicity of neurilemomas in the upper extremity. J Hand Surg Am 1987;12(2):307-11. 


\section{Jemds.com}

[9] July J, Guha A. Treatment of peripheral nerve tumours. CDK 2011;38(4):257-62.

[10] Kang HJ, Shin SJ, Kang ES. Schwannomas of the upper extremity. J Hand Surg Br 2000;25(6):604-7.

[11] Ozdemir 0, Kurt C, Coskunol E, et al. Schwannomas of the hand and wrist: long-term results and review of the literature. J Orthop Surg 2005;13(3):267-72.

[12] Kim SM, Seo SW, Lee JY, et al. Surgical outcome of schwannomas arising from major peripheral nerves in the lower limb. Int Orthop 2012;36(8):1721-5.

[13] Oberle J, Kahamba J, Richter HP. Peripheral nerve schwannomas--an analysis of 16 patients. Acta Neurochir (Wein) 1997;139(10):949-53.

[14] Strickland JW, Steichen JB. Nerve tumors of the hand and forearm. J Hand Surg Am 1977;2(4):285-91.

[15] Kransdorf MJ. Benign soft-tissue tumors in a large referral population: distribution of specific diagnoses by age, sex, and location. Am J Roentgenol 1995;164(2):395-402.

[16] Rockwell GM, Thoma A, Salama S. Schwannoma of the hand and wrist. Plast Reconstr Surg 2003;111(3):1227-32.

[17] Pęksa R, I'zycka-Swieszewska E, Rzepko R, et al. Osłoniaki nerwowe o'srodkowe i obwodowe-badania morfologiczne, immunohistochemiczne i analiza naczyniowa. Annales Academiae Medicae Gedanensis 2008;38:71-8.

\section{Original Research Article}

[18] Jerzy G, Roman R, Jerzy R. Peripheral nerve tumours in own material. Folia Neuropathol 2004;42(4):203-7.

[19] Ergun T, Lakadamyali H, Derincek A, et al. Magnetic resonance imaging in the visualization of benign tumors and tumor-like lesions of hand and wrist. Curr Probl Diagn Radiol 2010;39(1):1-16.

[20] Thawait SK, Chaudhry V, Thawait GK, et al. Highresolution MR neurography of diffuse peripheral nerve lesions. Am J Neuroradiol 2011;32(8):1365-72.

[21] Villanova JC, Woertler K, Narvaez JA, et al. Soft-tissue tumors update: MR imaging features according to the WHO classification. Eur Radiol 2007;17(1):125-38.

[22] Chhabra A, Soldatos T, Durand DJ, et al. The role of magnetic resonance imaging in the diagnostic evaluation of malignant peripheral nerve sheath tumors. Indian J Cancer 2011;48(3):328-34.

[23] Kubiena H, Entner T, Schmidt M, et al. Peripheral neural sheath tumors (PNST)-what a radiologist should know. Eur J Radiol 2013;82(1):51-5.

[24] Klijanienko J, Caillaud JM, Lagac'e R. Cytohistologic correlations in schwannomas (neurilemmomas), including "ancient," cellular, and epithelioid variants. Diagn Cytopathol 2006;34(8):517-22. 